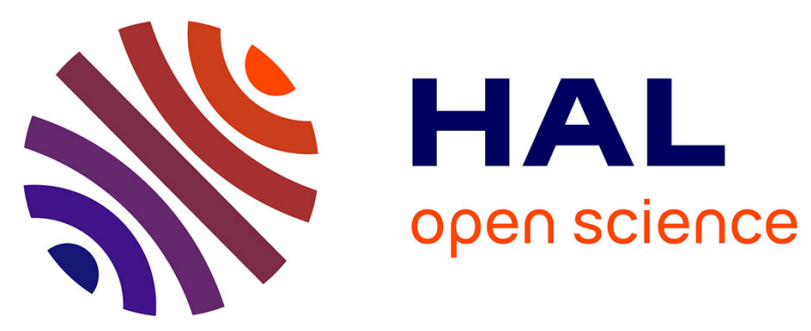

\title{
Frequency Scalable Model for MEMS Capacitive Shunt Switches at Millimeter Wave Frequencies
}

Vincent Puyal, Daniela Dragomirescu, Christina Villeneuve-Faure, Jinyu Jason Ruan, Patrick Pons, Robert Plana

\section{- To cite this version:}

Vincent Puyal, Daniela Dragomirescu, Christina Villeneuve-Faure, Jinyu Jason Ruan, Patrick Pons, et al.. Frequency Scalable Model for MEMS Capacitive Shunt Switches at Millimeter Wave Frequencies. IEEE Transactions on Microwave Theory and Techniques, 2009, 57 (11), p.2824-2833. hal-00591017

\section{HAL Id: hal-00591017 https://hal.science/hal-00591017}

Submitted on 6 May 2011

HAL is a multi-disciplinary open access archive for the deposit and dissemination of scientific research documents, whether they are published or not. The documents may come from teaching and research institutions in France or abroad, or from public or private research centers.
L'archive ouverte pluridisciplinaire HAL, est destinée au dépôt et à la diffusion de documents scientifiques de niveau recherche, publiés ou non, émanant des établissements d'enseignement et de recherche français ou étrangers, des laboratoires publics ou privés. 


\title{
Frequency Scalable Model for MEMS Capacitive Shunt Switches at Millimeter Wave Frequencies
}

\author{
Vincent Puyal, Member, IEEE, Daniela Dragomirescu, Member, IEEE, Christina Villeneuve, \\ Jinyu Ruan, Student Member, IEEE, Patrick Pons and Robert Plana, Senior Member, IEEE.
}

\begin{abstract}
This paper presents an approach to RF MEMS capacitive shunt switch design from K-band up to $\mathrm{W}$-band, based on the scalability of the RF MEMS switch with frequency. The parameters of the switch's equivalent circuit model also follow scaling rules. The measurement results of the fabricated switches show an excellent agreement with simulations which allow to validate the MEMS model in the entire band from $20 \mathrm{GHz}$ up to $94 \mathrm{GHz}$. This model is going to be used in phase shifter circuit design for antenna array applications. First $60-\mathrm{GHz}$ phase shifter results are also reported here.
\end{abstract}

Index Terms- RF-MEMS, Capacitive, Shunt Switches, Phase Shifters, Modeling.

\section{INTRODUCTION}

$\mathrm{R}$ ADIO Frequency Micro-Electro-Mechanical Systems (RF MEMS) are a new kind of passive circuit components, used in broad-band communication systems. They have multiple applications, such as varactors, switches and resonators.

RF MEMS micro-switches have demonstrated good performances in terms of isolation, loss, and power handling far better than those of conventional diodes. So, the purpose is to replace the currently used active circuits in systems by passive circuits (based on RF MEMS), and one of the challenges is to obtain RF circuits operating at very high frequencies (up to $94 \mathrm{GHz}$ for radar systems).

Table I [1-5] shows the state-of-the-art of integrated phase shifters. Note that RF MEMS phase shifters exhibit low insertion loss with very low phase error. The challenge is to design $60-\mathrm{GHz}$ phase shifters on a silicon circuit compatible substrate for future antenna array systems. Therefore, at first, a shunt capacitive switch model scalable up to millimeterwave frequencies has been developed from previous $20-\mathrm{GHz}$ MEMS measurements.

Manuscript received January 31, 2009. This work was supported by the French National Research Agency (Radio Soc Project, JC05-60832) and the Aeronautic and Space Research Foundation (LIMA Project).

Authors are with CNRS ; LAAS ; 7 avenue du colonel Roche, F-31077 Toulouse, France and Université de Toulouse ; UPS, INSA, INP, ISAE ; LAAS ; F-31077 Toulouse, France (corresponding author to provide phone: +33561336816; fax: +33561336969; e-mail: vpuyal@ laas.fr).
TABLE I

STATE-OF-THE-ART OF DIFFERENT PHASE SHIFTERS

\begin{tabular}{|c|c|c|c|c|c|c|}
\hline $\begin{array}{c}\text { Frequency } \\
(\mathrm{GHz})\end{array}$ & Type/bits & $\begin{array}{c}\text { Phase } \\
\text { error }\end{array}$ & $\begin{array}{c}\text { Insertion } \\
\text { loss } \\
(\mathrm{dB})\end{array}$ & Bulk & $\begin{array}{c}\text { Area } \\
\left(\mathrm{mm}^{2}\right)\end{array}$ & Ref. \\
\hline $75-110$ & MEMS/3 & $3^{\circ}$ & -2.7 & Glass & $5 \times 1.9$ & {$[1]$} \\
\hline $50-70$ & MEMS/2 & $5^{\circ}$ & -4.6 & Quartz & $2.1 \times 1.5$ & {$[2]$} \\
\hline $30-38$ & $\begin{array}{c}0.12 \mathrm{u} \\
\text { BiCMOS/4 }\end{array}$ & $7^{\circ}$ & +1 & $\mathrm{Si}$ & $0.9 \times 0.4$ & {$[3]$} \\
\hline $18-26$ & $\begin{array}{c}0.13 \mathrm{u} \\
\mathrm{CMOS} / 4\end{array}$ & $9.7^{\circ}$ & -3.8 & $\mathrm{Si}$ & $0.8 \mathrm{x} 0.6$ & {$[4]$} \\
\hline $55-65$ & $\begin{array}{c}65 \mathrm{~nm} \\
\mathrm{CMOS} / 4\end{array}$ & $9.2^{\circ}$ & -9.4 & $\mathrm{Si}$ & $/$ & {$[5]$} \\
\hline
\end{tabular}

Then this model has been extrapolated to build different RF MEMS models up to $94 \mathrm{GHz}$. The electrical model of RF MEMS is based on a RLC shunt circuit [6-8]. In Ref. [6], a parametric capacitive switch model based on the bridge width is shown. Compared to this last model, the new aspect is to introduce frequency scalability on the switch model to improve and simplify RF MEMS integrated circuit design at millimeter wave frequencies. Other approaches have been also published including the dynamical [9] or mechanical [10] aspects of RF MEMS.

Based on different graphs plotted in this paper, straightforward creation of an RF MEMS model is possible. Finally, to illustrate the results obtained when employing the electrical switch model, it is used to design $60-\mathrm{GHz}$ phase shifters. Preliminary results of this study were presented in [11].

\section{TECHNOLOGY FOR MILLIMETER WAVE MEMS}

\section{A. Fabrication Methodology}

The fabrication process flow of RF-MEMS capacitance microswitches is depicted in figure 1 and the steps are described below.

(a) Each process begins with a cleaning step to remove the chemical oxide.

(b) On the clean silicon substrate, a $20 \mu \mathrm{m}$ thick BenzoCycloButene (BCB) layer is deposited. 


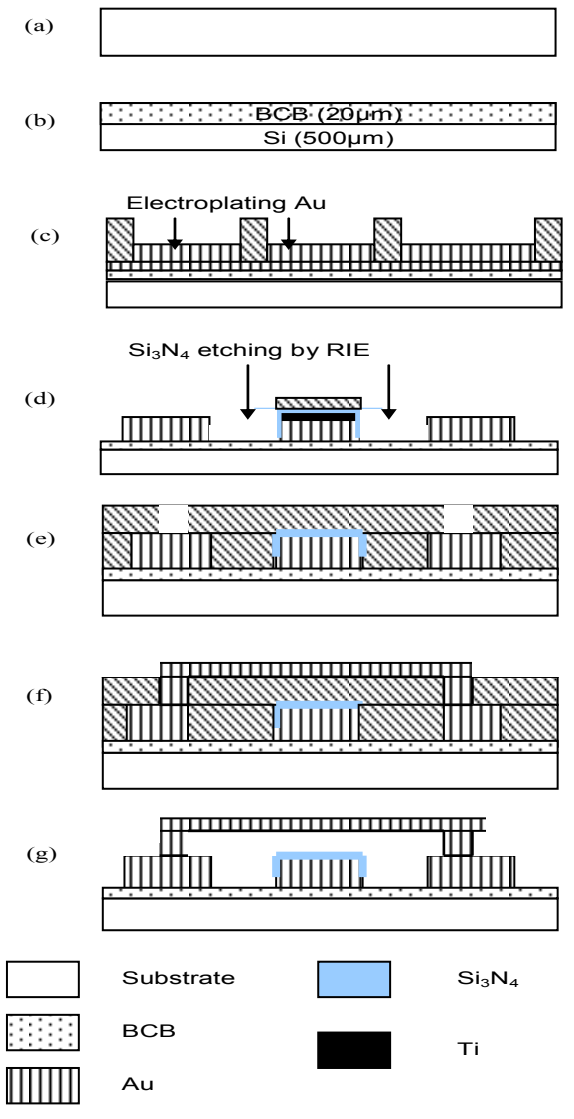

Fig. 1. RF-MEMS micro-switch fabrication process.

(c) CoPlanar Waveguide (CPW) fabrication: a Ti/Au bilayer is evaporated serving as seed layer for a $2.5 \mu \mathrm{m}$ thick electroplating gold layer grown in a photoresist mould created previously. Then, the seed layer is chemical etched between lines.

(d) A $100 \mathrm{~nm}$ thick $\mathrm{Ti}$ layer is evaporated on the $\mathrm{Au} \mathrm{CPW}$ and a $250 \mathrm{~nm}$ thick $\mathrm{Si}_{3} \mathrm{~N}_{4}$ layer is deposited by Plasma-Enhanced Chemical Vapor Deposition (PECVD). These layers are patterned using photolithography, Reactive Ion Etching (RIE) and wet etching.

(e) Two steps of planarization: a $2.5 \mu \mathrm{m}$ thick photoresist layer is spin coated, pre-baked and after photolithography, hard-baked. The same steps are used for gap filling and the sacrificial layer.

(f) Over this sacrificial layer, a $100 \mathrm{~nm}$ thick Au layer is evaporated and $1.9 \mu \mathrm{m}$ thick $\mathrm{Au}$ is electroplated. This bi-layer, which forms the bridge over the CPW, is patterned with photolithography and chemical etching.

(g) The final step consists in releasing the switches. The sacrificial layer is removed using successive chemical baths. Finally, the MEMS is dried.

This process provides MEMS switches with a flat and low stress bridge over the CPW line. With this process various classes of structures are fabricated as, for example,
RF capacitive micro-switches, Single Pole Double Throw (SPDT) switches, switched line phase shifters and loaded line phase shifters.

\section{B. Description of the switch}

The switch structure (Fig. 2) is a RF MEMS capacitive shunt switch [12]. It consists of a $50 \Omega$ Grounded CoPlanar Waveguide (GCPW) over which a metal membrane is suspended at a height of $3 \mu \mathrm{m}$. The membrane consists of two main elements:

- the bridge having two states, corresponding to two capacitance values (up state or down state),

- two actuation electrodes located on each side of the bridge.

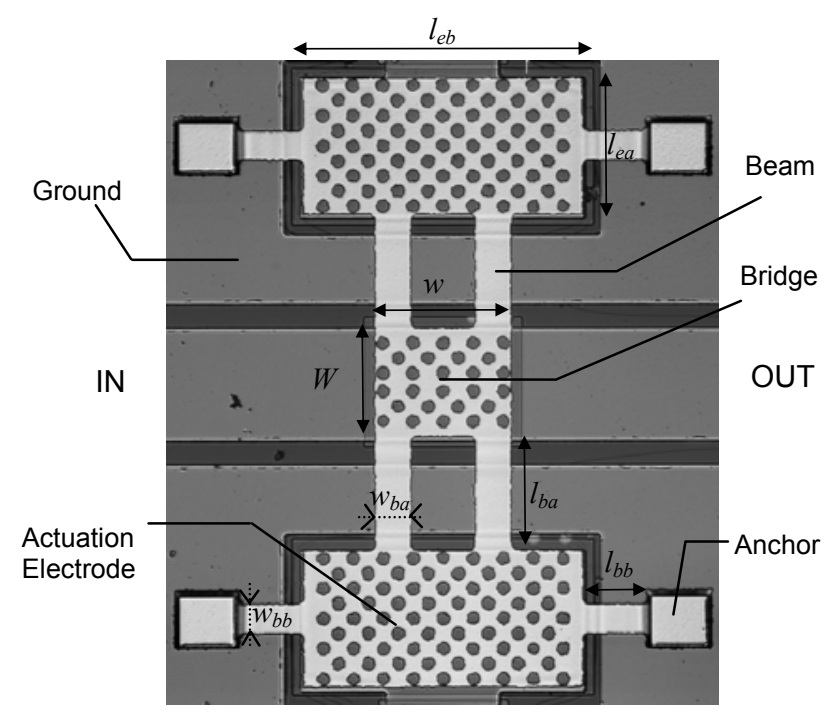

Fig. 2. Microphotograph of the fabricated reference switch.

A layer of silicon nitride of $0.25 \mu \mathrm{m}$ thickness is placed between the bridge and the signal line of the coplanar waveguide line. The thickness of the dielectric partially defines the down state capacitance value. Actuation is provided by a voltage (around $30 \mathrm{~V}$ ) between the bridge and the different under-layer structures (electrodes and signal line). The bridge capacitance depends on the bridge area ( $w \mathrm{x}$ $\left.W \mu \mathrm{m}^{2}\right)$ as shown in the switch microphotograph in figure 2 .

\section{RF MEMS MODELING}

\section{A. Electrical Part}

To design RF MEMS phase shifter circuits, an accurate wideband RF MEMS model is needed. The model (Fig. 3) is based on a classic $R L C$ equivalent circuit [13] with two short series sections of transmission line (t-line). To simplify the model, a scaling parameter $K_{s}$ is defined according to [14]. To build this model, previous simulation and measurement results of 20-GHz fabricated RF-MEMS shunt switches are used. 


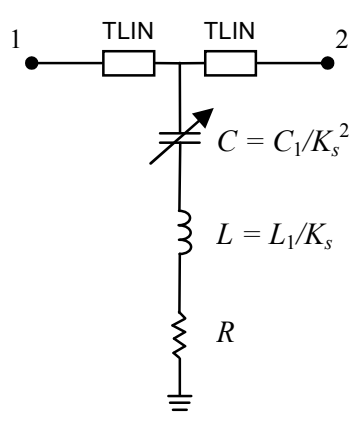

Fig. 3. Electrical model of the RF MEMS capacitive shunt switch.

The bridge capacitance is $80 \mathrm{fF}$ in up state, and $2300 \mathrm{fF}$ in down state for a $20-\mathrm{GHz}$ MEMS $\left(K_{s}=1\right)$. The series resistance is equal to $0.1 \Omega$. The $\mathrm{S}$ parameters of the reference switch show that it has a very low insertion loss of $0.27 \mathrm{~dB}$ (including access lines) and excellent isolation of $48 \mathrm{~dB}$ (Fig. 4) at $20 \mathrm{GHz}$. These positive results validate the technology and show their potential concerning integration into circuits.

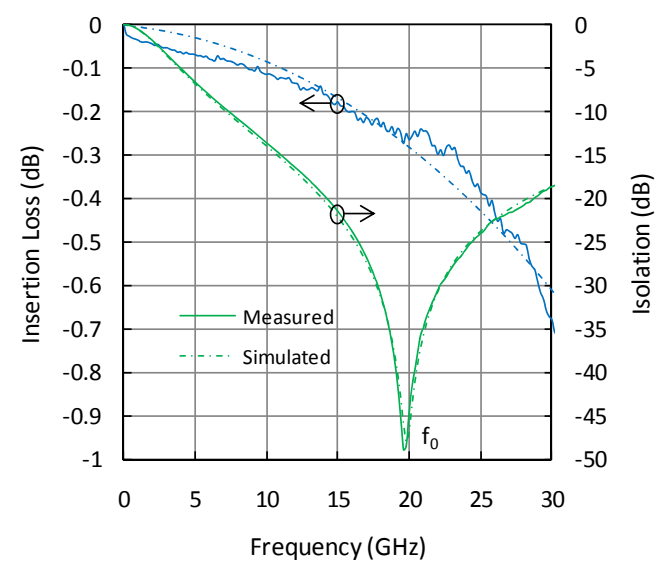

Fig. 4. Insertion loss and isolation of the reference MEMS $\left(\mathrm{K}_{\mathrm{s}}=1\right)$.

The first model at $20 \mathrm{GHz}$ has been extrapolated up to $94 \mathrm{GHz}$. The scaling parameter $K_{s}$ is defined as:

$$
K_{s, x}=\frac{w_{1}}{w_{x}}=\frac{W_{1}}{W_{x}} .
$$

The letter $x$ denotes the considered switch $(x=1$ for M1 switch, 2 for M2 switch, 3 for M3 switch, etc.)

Note that in all sections where $x$ is not explicity given, it remains unchanged $\left(K_{s}=K_{s, x} ; w=w_{x} ; W=W_{x} ;\right.$ etc. $)$.

When $K_{s}=1$, the MEMS dimensions correspond to the (previously measured) reference switch (20-GHz switch). Hence, the reference bridge dimensions are $200 \mu \mathrm{m} \times 160 \mu \mathrm{m}$ $\left(w_{1} \times W_{1}\right)$.

The scaling parameter is applied to all dimensions (Fig. 2) of the switch structure except for the vertical one: the metal thickness and the bridge height are constant. Consequently, beam dimensions (1b) and actuation electrode dimensions (1c) are also reduced according to

$$
\begin{gathered}
K_{s, x}=\frac{l_{b a, 1}}{l_{b a, x}}=\frac{l_{b b, 1}}{l_{b b, x}}=\frac{w_{b a, 1}}{w_{b a, x}}=\frac{w_{b b, 1}}{w_{b b, x}}, \\
K_{s, x}=\frac{l_{e a, 1}}{l_{e a, x}}=\frac{l_{e b, 1}}{l_{e b, x}} .
\end{gathered}
$$

\section{Capacitance}

The capacitance is represented by the bridge area. The down-state capacitance is

$$
C_{\text {down }}=\frac{\varepsilon_{0} \times \varepsilon_{r} \times A}{t_{d}}
$$

where $\varepsilon_{0}$ is the electric constant, $A$ the area of the bridge, $t_{d}$ the dielectric thickness $(0.3 \mu \mathrm{m})$ and $\varepsilon_{\mathrm{r}}$ the relative permittivity (6.5).

The up-state capacitance [14] is

$$
C_{u p}=\frac{\varepsilon_{0} \times A}{g+\frac{t_{d}}{\varepsilon_{r}}}
$$

where $g$ is the air gap $(3 \mu \mathrm{m})$ between the dielectric and the bridge.

The capacitances of the device scale according to

$$
C=\frac{C_{1}}{K_{s}^{2}}
$$

with $C_{1}$ the capacitance of the 20-GHz MEMS.

\section{Inductance}

The series inductance is mainly formed by the beams of the RF MEMS switch. The equation for the inductance [15] of a rectangular conductor is

$$
L(p H)=2 l_{c} \times 10^{-1} \times\left[\ln \left(\frac{2 l_{c}}{w_{c}+t_{c}}\right)+0.5+0.224\left(\frac{w_{c}+t_{c}}{l_{c}}\right)\right]
$$

where $l_{c}$ is the length (in $\mu \mathrm{m}$ ), $w_{c}$ the width and $t_{c}$ the thickness of the conductor.

After some calculations, we obtain an effective parameter $K$ ' that equals to $L / L_{1}$ for each inductance. This factor depends on the inductance size. Reference [14] shows the different $K$, parameters obtained versus $K_{s}$. We can conclude that

$$
L \approx \frac{L_{1}}{K_{s}} \quad \text { with } K_{s}<4
$$

where $L_{1}$ is the inductance of the 20-GHz MEMS.

\section{Resistance}

The series resistance is principally due to the conductor loss inside the beams.

The series loss $R$ of a conductor is calculated from the material's resistivity $\rho$ :

$$
R=\frac{\rho l_{c}}{w_{c} t_{c}} .
$$

where $l_{c}$ is the length, $w_{c}$ the width and $t_{c}$ the thickness of the conductor.

It's straightforward to calculate the DC value but, at high frequencies, the effective area $w_{c} t_{c_{-} \text {eff }}$ decreases because the 
skin effect becomes relevant. So, when frequency increases (decrease of $K_{s}$ ), the area $w_{c} t_{c}$ and the length $l_{c}$ decrease. That's why, it is difficult (for a first, simple model) to determine specifically the part of each effect. Indeed, $\mathrm{Si}_{3} \mathrm{~N}_{4}$ dielectric loss is added and the model becomes quite complex.

\section{Transmission Line}

The two t-line sections are of length $l_{T L I N}$ given by:

$$
l_{\text {TLIN }}=\frac{w_{1}}{2 K_{s}} \text {. }
$$

Their characteristic impedances are equal to $50 \Omega$. Other parameters (as dielectric loss and conductor loss) are included within the model of the microwave circuit simulator (ADS) and depend on frequency.

The resonance frequency $f_{0}$ [16] (maximum isolation) is inversely proportional (9) to the square root of the $L C$ factor

$$
f_{0}=\frac{1}{2 \pi \sqrt{L C}} \text {. }
$$

When dimensions decrease, the series inductance and the down-state capacitance drop; so, the resonance frequency increases.

With (4) and (6), equation (9) becomes

$$
\begin{gathered}
f_{0} \approx f_{01} K_{s}^{3 / 2}, \\
\text { where } f_{01}=\frac{1}{2 \pi \sqrt{L_{1} C_{1}}} .
\end{gathered}
$$

So, the scaling parameter is given by

$$
K_{s} \approx\left(\frac{f_{0}}{f_{01}}\right)^{2 / 3} .
$$

For example, if a $60-\mathrm{GHz}$ MEMS is to be designed, $\mathrm{f}_{0}=60 \mathrm{GHz}, \mathrm{f}_{01}=20 \mathrm{GHz}$, so $K_{s}=2.08$ from (12). Thus, all dimensions of the reference switch have to be divided by 2.08 .

TABLE II

RF MEMS MODELS VERSUS $\mathrm{K}$

\begin{tabular}{|l|c|c|c|c|c|}
\hline $\begin{array}{c}\text { Name } / w \times W \\
\left(\mu \mathrm{m}^{2}\right)\end{array}$ & $K_{s}$ & $\begin{array}{c}C_{u p} \\
(\mathrm{fF})\end{array}$ & $\begin{array}{c}C_{\text {down }} \\
(\mathrm{fF})\end{array}$ & $\begin{array}{c}L \\
(\mathrm{pH})\end{array}$ & $\begin{array}{c}F_{o} \\
(\mathrm{GHz})\end{array}$ \\
\hline $\mathrm{M} 1 / 200 \times 160$ & 1 & 80 & 2300 & 28 & 20 \\
\hline $\mathrm{M} 2 / 138 \times 110$ & 1.45 & 38 & 1090 & 19 & 35 \\
\hline $\mathrm{M} 3 / 96 \times 77$ & 2.08 & 19 & 530 & 13 & 60 \\
\hline $\mathrm{M} 4 / 82 \times 65$ & 2.45 & 13 & 380 & 11 & 77 \\
\hline $\mathrm{M} 5 / 71 \times 57$ & 2.8 & 10 & 290 & 10 & 94 \\
\hline
\end{tabular}

Table II summarizes the different simulated values using this model. The first model has been extrapolated up to $94 \mathrm{GHz}$. This model shows that using a scaling parameter $\left(K_{s}\right)$ simplifies the search for the optimum frequency response when the resonance frequency is specified.

\section{B. Mechanical Part}

The reference switch (20-GHz MEMS) has a low residual stress of 5-7 MPa and a spring constant of 22-27 N/m. The air gap is around $2.5 \mu \mathrm{m}$ (and thus differs from the predicted $3 \mu \mathrm{m}$ ) for the first fabricated MEMS.

Now, it is interesting to investigate the actuation voltage versus the scaling parameter $K_{s}$. The "pull-in" (or "pulldown") voltage is defined as the applied voltage for collapse the bridge on the signal line.

The "pull-in" voltage [17], for a central single actuation, when the effect of the dielectric layer is neglected, is given by

$$
V_{p u l l-i n, x}=\sqrt{\frac{8 k_{x}}{27 \varepsilon_{0} W_{x} w_{x}} g_{0}{ }^{3}}
$$

where $k_{x}$ is the effective spring constant of the RF MEMS and $\mathrm{g}_{0}$ the bridge height in up-state. From (13):

$$
\begin{array}{r}
\left(\frac{V_{p u l l-i n, x}}{V_{p u l l-i n, 1}}\right)^{2}=\frac{k_{x}}{W_{x} w_{x}} \times \frac{W_{1} w_{1}}{k_{1}}, \\
\text { so } V_{p u l l-i n, x}=\sqrt{\frac{k_{x}}{k_{1}}} \times V_{p u l l-i n, 1} \times K_{s, x}
\end{array}
$$

In the equation (15), the "pull-in" voltage $\mathrm{V}_{\text {pull-in }}$ increases according the scaling parameter $K_{s}$ and the square root of the ratio of effective spring constants $k_{\mathrm{x}} / k_{1}$.

\section{MOdEL RESUltS}

\section{A. Capacitance Measurements}

The experimental results of the first measurement step of the RF MEMS switches described previously are presented here. In figure 5 , the results of capacitance measurement of a 60-GHz MEMS $\left(K_{s}=2.08\right)$ are shown $\left(C_{u p}=20 \mathrm{fF}, C_{\text {down }}=\right.$ $\left.550 \mathrm{fF}, C_{o n} / C_{o f f}=28\right)$.

At the beginning, the bias voltage is $0 \mathrm{~V}$ : the switch is in up-state (small capacitance close to $0-\mathrm{pF}$ line). Then, the bias voltage is increased linearly up to $44 \mathrm{~V}$. Around $15 \mathrm{~V}$, the central bridge begins to actuate and the capacitance changes to $0.25 \mathrm{pF}$. When the voltage equals $30 \mathrm{~V}$, the lateral electrodes finish to descend and the actuation is complete (down-state). Here, the capacitance is $0.55 \mathrm{pF}$. Finally, the bias voltage is decreased linearly down to $-44 \mathrm{~V}$ and finally increased again to $0 \mathrm{~V}$. A hysteresis appears on the graph; Thus, the voltages necessary to change from down-state to up-state and viceversa are different $\left(\mathrm{V}_{\text {pull-in }}=30 \mathrm{~V}, \mathrm{~V}_{\text {pull-out }}=16 \mathrm{~V}\right)$. 


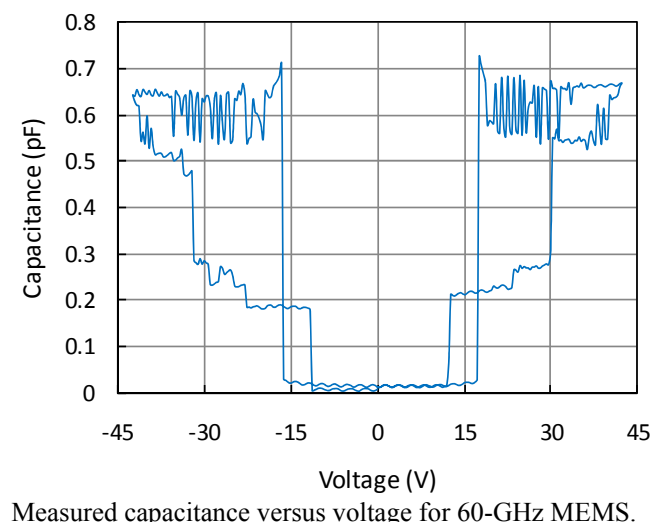

Fig. 5. Measured capacitance versus voltage for 60-GHz MEMS.

For all switches, a comparison between the theoretical and the experimental down-state capacitance (Tab. III) is done. For each kind of RF MEMS, an average of about 20 measurements is shown.

Some very small differences can appear between the capacitance values in the Table III and the capacitance values extracted from $\mathrm{S}_{21}$ graphs (cf. sections III.B. and III.C) because the wafer measured isn't the same in both cases.

TABLE III

DOWN-STATE CAPACITANCES

\begin{tabular}{|c|c|c|}
\hline \multicolumn{3}{|c}{ DowN-STATE CAPACITANCES } \\
\hline RF MEMS & $\begin{array}{c}\text { Experimental } \mathrm{C}_{\text {down }} \\
(\mathrm{fF})\end{array}$ & $\begin{array}{c}\text { Theoretical } \mathrm{C}_{\text {down }} \\
(\mathrm{fF})\end{array}$ \\
\hline M1 & 2155 & 2300 \\
\hline M2 & 1050 & 1090 \\
\hline M3 & 525 & 530 \\
\hline M4 & 375 & 380 \\
\hline M5 & 265 & 290 \\
\hline
\end{tabular}

\section{B. S-parameter Measurements}

The RF performance of each MEMS from M1 up to M5 are presented in this section.

The RF characterization of the switches requires adequate measurement equipment as well as special care in the measurement setup. The switch characteristics were measured using on-wafer probing. The measurement setup is composed of:

- a 65-GHz Anritsu 37397C VNA (Vector Network Analyser),

- a personal computer that allows to display S-parameter waveforms and download S-parameter files (for electrical simulations),

- 65-GHz probes and $1 \mathrm{~m} \mathrm{~V}$-type coaxial cables.

Above $65 \mathrm{GHz}, 110-\mathrm{GHz}$ probes, an Anritsu mixer and source modules have to be used to measure from $65 \mathrm{GHz}$ to
$110 \mathrm{GHz}$ (for switches M4 and M5).

A $100-\mathrm{V}$ bias tuning voltage module allows to easily adjust the actuation voltage between 0 and $45 \mathrm{~V}$.

For all S-parameter presented measurements, the CPW access lines are de-embedded.

The microphotographs of all switches from M1 $(20 \mathrm{GHz}-$ MEMS) up to M5 (94 GHz-MEMS) are presented in figure 6. Insertion loss and isolation of all switches versus frequency are shown in figure 7.

The Tab. IV resumes all characteristics of the measured RF MEMS. The dimensions of the switches are comprised between $800 \mu \mathrm{m} \times 1000 \mu \mathrm{m}$ (for the largest one) and $350 \mu \mathrm{m}$ $\times 340 \mu \mathrm{m}$ (for the smallest one).

TABLE IV

RF MEMS CHARACTERISTICS

\begin{tabular}{|l|c|c|c|c|c|c|}
\hline Switch & $\begin{array}{c}\text { Size } \\
(\mu \mathrm{m} \times \mu \mathrm{m})\end{array}$ & $\begin{array}{c}\text { Insertion } \\
\text { Loss } \\
(\mathrm{dB})\end{array}$ & $\begin{array}{c}\text { Isolation } \\
(\mathrm{dB})\end{array}$ & $\begin{array}{c}\text { Operating } \\
\text { Band } \\
(\mathrm{GHz})\end{array}$ & $\begin{array}{c}\text { Resonance } \\
\text { Frequency } \\
(\mathrm{GHz})\end{array}$ & $\begin{array}{c}\text { Actuation } \\
\text { Voltage } \\
(\mathrm{V})\end{array}$ \\
\hline M1 & $800 \times 1000$ & 1.1 & 35 & $14-24$ & 19.5 & 20 \\
\hline M2 & $600 \times 600$ & 0.7 & 32 & $27-42$ & 34 & 25 \\
\hline M3 & $450 \times 450$ & 0.6 & 32 & $52-65$ & 60 & 30 \\
\hline M4 & $400 \times 350$ & 0.3 & 25 & $68-88$ & 78 & 35 \\
\hline M5 & $350 \times 340$ & 0.3 & 27 & $86-102$ & 94.5 & 35 \\
\hline
\end{tabular}

Insertion loss and isolation of the switches are defined at the modeled resonance frequency (For example, for M1, at $20 \mathrm{GHz}$ and not at $19.5 \mathrm{GHz}$ ). The capacitive shunt switches present good insertion loss (average value: $0.6 \mathrm{~dB}$ ) and excellent isolation (average value: $30 \mathrm{~dB}$ ). The operating band (specified by a $20-\mathrm{dB}$ isolation level) of the switch is about $15 \mathrm{GHz}$. The resonance frequency is close to the predicted one for each switch $( \pm 1 \mathrm{GHz})$. The actuation voltage lies between $20 \mathrm{~V}$ and $35 \mathrm{~V}$.

Note that the many holes present on the top metal layer (bridge and electrodes) is used to facilitate the removing of the sacrificial layer during the switch fabrication. For the MEMS $\mathrm{M} 1$, their impact on the effective bridge area is negligible, whereas for smaller MEMS, they decrease it slightly. 


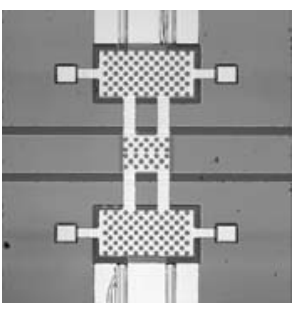

M1

(20-GHz MEMS)

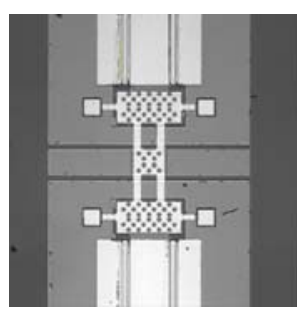

$\mathrm{M} 2$

(35-GHz MEMS)

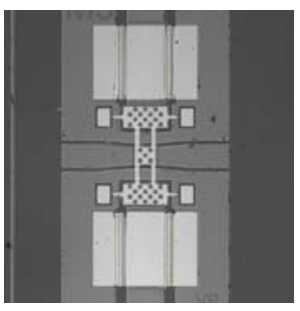

$\mathrm{M} 3$

(60-GHz MEMS)

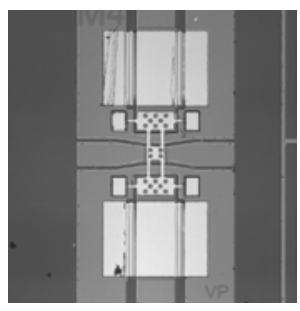

M4

(77-GHz MEMS)

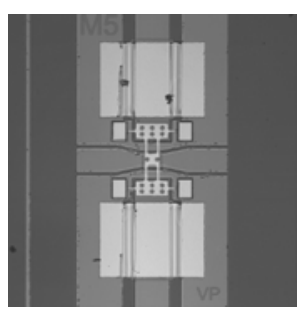

M5

(94-GHz MEMS)

Fig. 6. RF MEMS microphotographs (using the same objective).

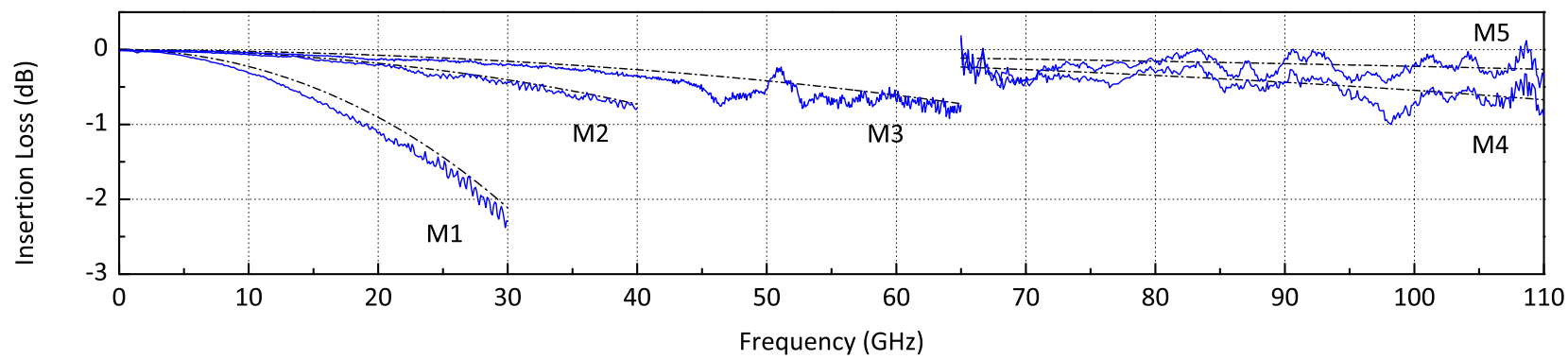

(a)

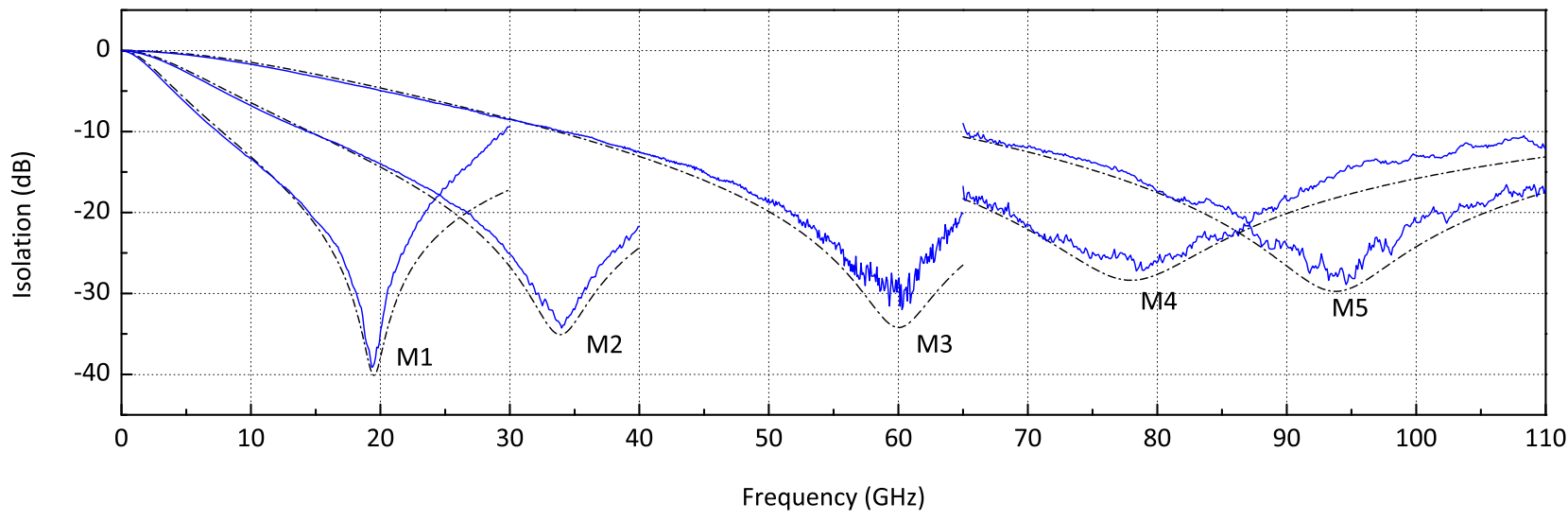

(b)

Fig. 7. Insertion loss (a) and isolation (b) of RF MEMS.

The measured S21 parameter is represented by the solid line. The fitted S21 parameter (with the electrical model from figure 4) is the dotted line.

\section{Scalability}

In this section, the dependency of most of the switch parameters on $K_{s}$ is described and compared to the theoretical model. All model parameters have been extracted from previously fitted graphs $\left(C_{\text {down }}, L, R\right.$ from the isolation graph and $C_{u p}$ from the insertion loss graph).

Figure 8 shows the up-state capacitance $C_{u p}$ versus the scaling parameter $K_{s}$. Good agreement with the model equation (4) is observable. In this case, from the fitted equation $\left(\mathrm{y}=151 \mathrm{x}^{-2}\right)$, the parameter $C_{1}$ is found to be $151 \mathrm{fF}$ (Theory: $80 \mathrm{fF}$ ). The difference between the experimental value and the theory value of the capacitance can be explained by the difference of sacrificial layer thickness (i.e. bridge height) used in simulation $(3 \mu \mathrm{m})$ and obtained after fabrication $(2-2.5 \mu \mathrm{m})$.

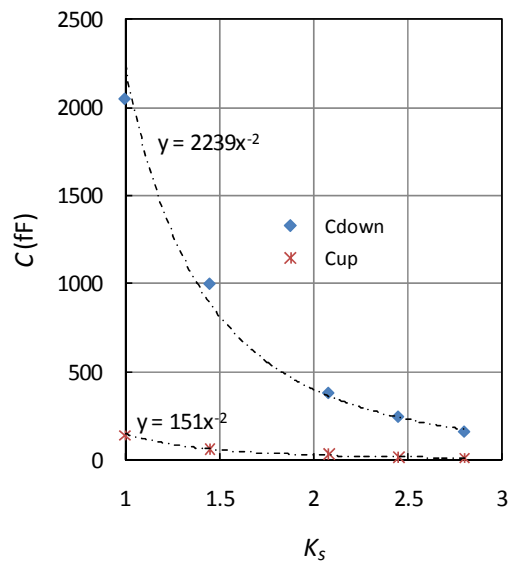

Fig. 8. Capacitance in up-state and down-state versus $K_{s}$. 
Figure 8 also shows the down-state capacitance $C_{\text {down }}$ versus the scaling parameter $K_{s}$. An excellent agreement with the model equation (4) is observable as well. In this case, from the fitted equation $\left(\mathrm{y}=2239 \mathrm{x}^{-2}\right)$, the parameter $C_{1}$ is equal to $2239 \mathrm{fF}$ (Theory: $2300 \mathrm{fF}$ ).

So, the capacitances of the switch in up-state and in down-state as a function of $K_{s}$ are:

$$
\begin{array}{r}
C_{u p}(f F)=\frac{151}{K_{s}{ }^{2}}, \\
\text { and } C_{\text {down }}(f F)=\frac{2239}{K_{s}{ }^{2}} .
\end{array}
$$

As seen previously, the capacitance of the switch changes between the up-state and the down-state. Now, analysis of the two last static parameters, the series inductance and the series resistance, is done.

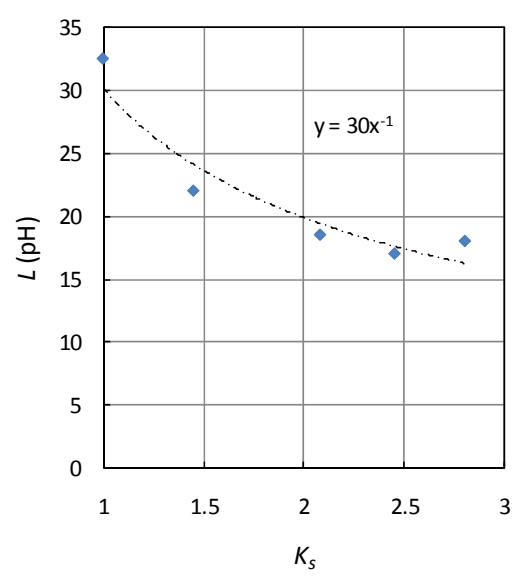

Fig. 9. Series inductance versus $K_{s}$.

The evolution of the series inductance (cf. figure 9) confirms the model predictions. The inductance decreases according to $1 / K_{s}$, which corresponds to model equation (6). From the fitted graph $\left(\mathrm{y}=30 \mathrm{x}^{-1}\right)$, the obtained parameter $L_{1}$ is $30 \mathrm{pH}$ (Theory: $32 \mathrm{pH}$ ) and the inductance is

$$
L(p H)=\frac{30}{K_{s}} .
$$

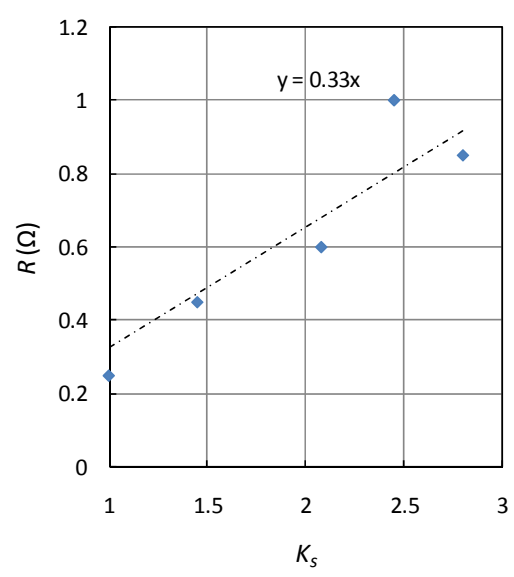

Fig. 10. Series resistance versus $K_{s}$.
Figure 10 shows that the series resistance of the shunt switches increase linearly. That differs from the first resistance equation (7) that assumes a constant value (same shape for all MEMS). Indeed, in this case, the skin effect is very pronounced when the frequency approach $100 \mathrm{GHz}$.

The fitted equation $(\mathrm{y}=0.33 \mathrm{x})$ allows to write that:

$$
R(\Omega)=0.33 \times K_{s} .
$$

In the next figure (Fig. 11), the evolution of the actuation voltage is shown. It is interesting to note that $\mathrm{V}_{\text {pull-in }}$ increases linearly with $K_{s}(\mathrm{y}=7.8 \mathrm{x})$ as indicated in (20a):

$$
\begin{gathered}
V_{\text {pull-in, } x}(V)=7.8 \times K_{s, x} \\
\text { and } \quad V_{\text {pull-in, } x}=V_{\text {pull-in }, 1} \times K_{s, x} .
\end{gathered}
$$

Combining (20b) and (15) yields the scaling law that applies to the effective spring constant $k_{x}$ as

$$
\sqrt{\frac{k_{x}}{k_{1}}}=1,
$$

and thus $\quad k_{x}=k_{1}$.

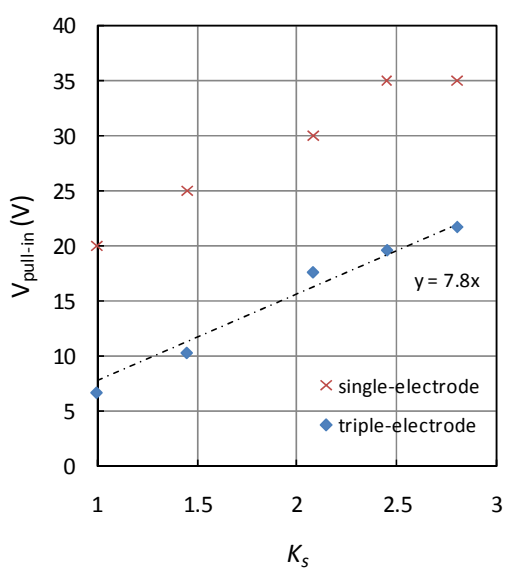

Fig. 11. Actuation voltage versus $K_{s}$.

For a triple actuation, the effective spring constant seems to be constant for all switches and the "pull-in" voltage is very low (7-22 V).

Note that, in Fig. 11, the "pull-in" voltage for a single central actuation (20-35 V) is also reported for each switch.

Figure 12 shows that the resonance frequency $\left(\mathrm{y}=20 \mathrm{x}^{1.5}\right)$ fits well with the electrical model (10). This result depends directly on the result for $\mathrm{C}_{\text {down }}$.

The relationship

$$
f_{0}=20 K_{s}^{3 / 2}
$$

is obtained from the fit.

So

$$
K_{s}=\left(\frac{f_{0}}{20}\right)^{2 / 3} \text {. }
$$




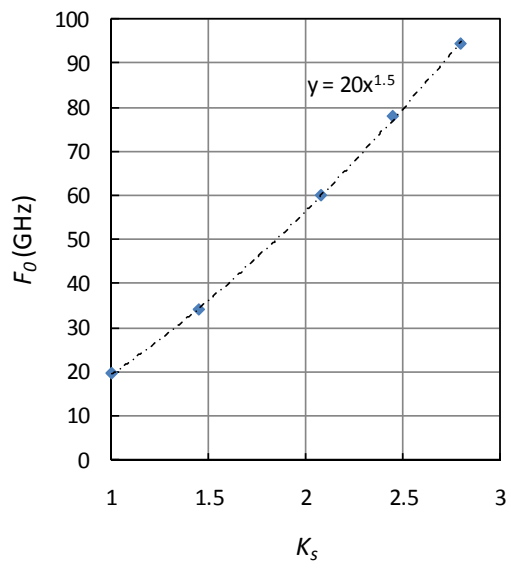

Fig. 12. Resonance frequency versus $K_{s}$.

To resume, from (16), (17), (18), (19) and (23) the parameters of the experimental model can be expressed as functions of frequency by:

$$
\begin{aligned}
& C_{u p}(f F)=151 \times\left(\frac{f_{0}}{20}\right)^{-4 / 3}, \\
& C_{\text {down }}(f F)=2239 \times\left(\frac{f_{0}}{20}\right)^{-4 / 3}, \\
& L(p H)=30 \times\left(\frac{f_{0}}{20}\right)^{-2 / 3}, \\
& R(\Omega)=0.33 \times\left(\frac{f_{0}}{20}\right)^{2 / 3} \text { and } \\
& l_{T L I N}(\mu m)=100 \times\left(\frac{f_{0}}{20}\right)^{-2 / 3} .
\end{aligned}
$$

with $f_{0}(\mathrm{GHz})$ being the desired resonance frequency of the MEMS.

In the previous equations, it is interesting to note that all model parameters depend only on $f_{0}$ so the model is truly frequency scalable.

The insertion loss (fig. 13) of the switches decreases according to the scaling parameter $K_{s}$. Compared to the 20-GHz MEMS, the insertion loss of the 77-GHz MEMS is very small (about one quarter).

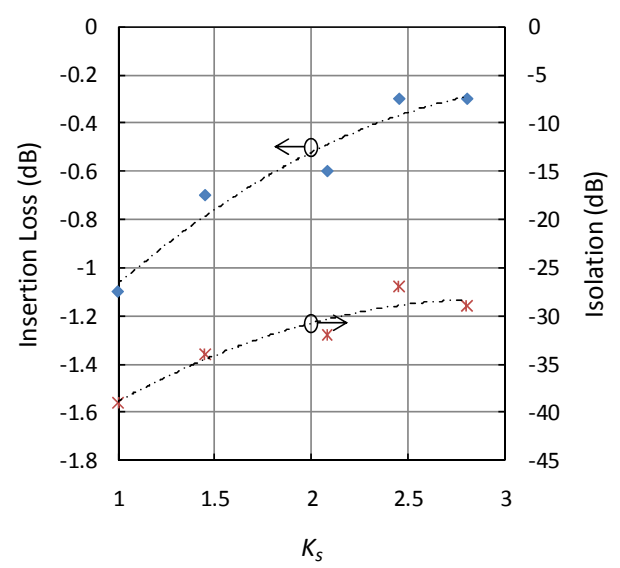

Fig. 13. Insertion loss and isolation versus $K_{s}$.

The isolation (fig. 13) decreases, but the value remains below $27 \mathrm{~dB}$ at resonance frequency. The graphs presented in this section simplify considerably the task of parameterizing the model for a future RF MEMS switch working at another frequency.

Consider the case of the design of an RF MEMS based impedance tuner at $50 \mathrm{GHz}$. The first step is to design a 50-GHz MEMS. With the model presented, it is not necessary to fabricate a test structure of the MEMS. It is sufficient to get the scaling parameter $K_{s}$ from fig. 12 . In this particular case, in, the $K_{s}$ obtained is 1.8 . Then, the value can be applied to the other graphs to find all model parameters $\left(C_{u p}=30 \mathrm{fF} ; C_{\text {down }}=\right.$ $500 \mathrm{fF} ; L=18 \mathrm{pH} ; R=0.6 \Omega$ ).

Note that, while the graphs presented depend in part on the technology, the methodology can be easily transferred.

\section{V.APPLICATIONS}

One future use of the proposed design methodology is to realize phase shifters based on RF MEMS. This approach allows to model and predict the behavior of the entire phase shifter. This circuit is needed for smart antennas for wireless sensor networks.

A 1-bit V-band phase shifter loaded line type has been developed from the shown RF MEMS model.

For this first design, the circuit has been designed to provide a phase shift of $22.5^{\circ}$. It uses capacitive shunt switches and $50 \Omega$ GCPW access lines. It has been optimized for operation at $60 \mathrm{GHz}$.

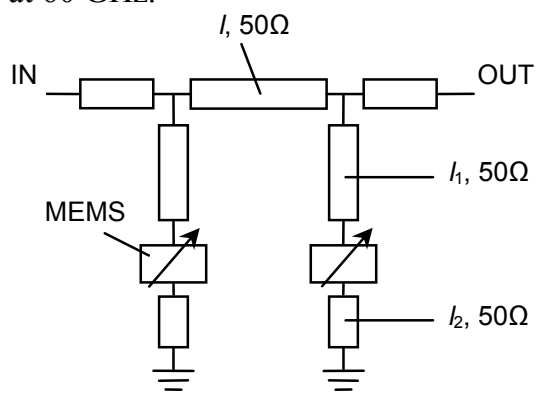

a) 


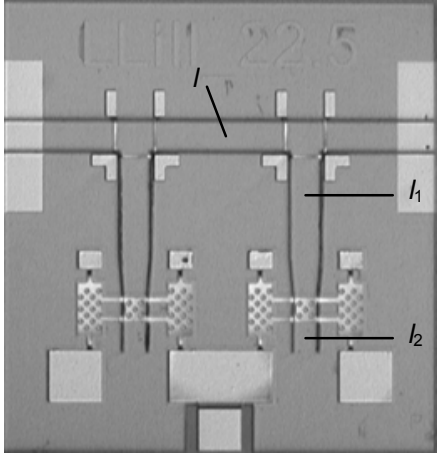

b)

Fig. 14. Fabricated 60-GHz loaded line phase shifter.

Electrical schematic (a) and microphotograph (b).

The designed loaded-line phase shifter (Fig. 14) operates in class III [18]. The circuit uses two RF MEMS switches. The main line is loaded with two stubs whose lengths depend on the state of the switches $\left(l_{1}+l_{2}\right.$ in up-state, $l_{1}$ in down-state). This load difference provides the two output phase states. The stub lengths are calculated based on:

$$
\begin{aligned}
& \theta=90^{\circ}, \\
& \theta_{1}=\tan ^{-1}\left(B_{1} / Y_{s}\right), \\
& \theta_{2}=\tan ^{-1}\left(B_{2} / Y_{s}\right)-\theta_{1}, \\
& B_{1}=-B_{2}=Y_{0} \tan (\Delta \Phi / 2),
\end{aligned}
$$

where $\theta$ is the electrical length of the line $l, \theta_{1}$ the electrical length of the line $l_{1}, \theta_{2}$ the electrical length of the line $l_{2}, B_{1}$ and $B_{2}$ are the complex-conjugate loading susceptances, $Y_{s}$ the characteristic admittance of the stub line, and $\Delta \Phi$ the desired phase shift.

The Class III architecture was chosen because it has a constant loss per bit and relatively constant phase response.

The Fig. 15 shows the good performance of the $60-\mathrm{GHz}$ phase shifters designed for future antenna array systems.

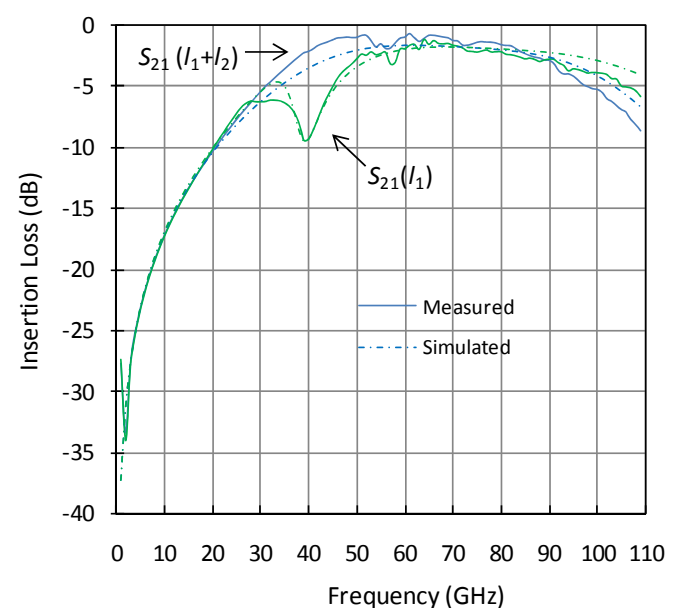

(a)

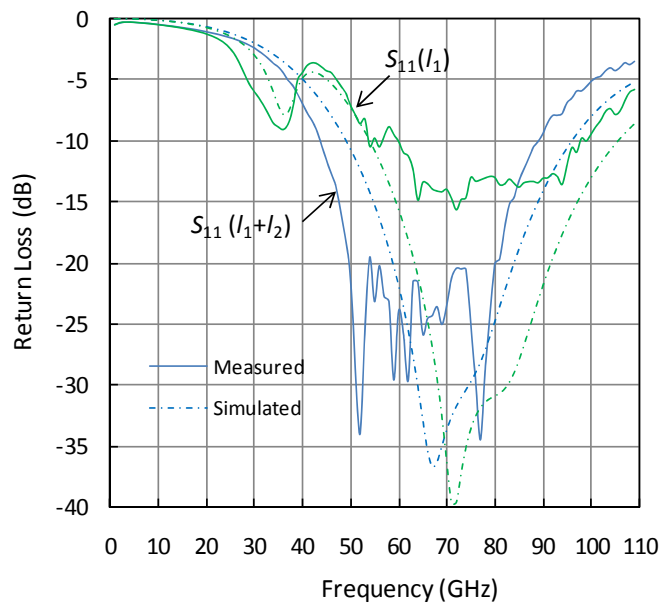

(b)

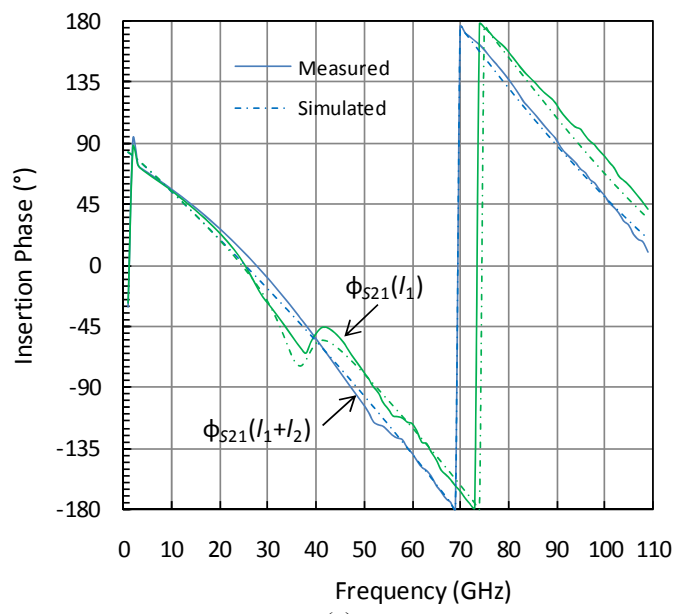

(c)

Fig. 15. S-parameter measurements of the $60-\mathrm{GHz}$ loaded line phase shifter. Insertion loss (a), return loss (b) and insertion phase (c).

The measured phase shifter presents a low insertion loss $\left(1.1 \mathrm{~dB}\right.$ in $l_{1}+l_{2}$ state and $1.9 \mathrm{~dB}$ in $l_{1}$ state $)$ and a good return loss $\left(24 \mathrm{~dB}\right.$ in $l_{1}+l_{2}$ state and $11 \mathrm{~dB}$ in $l_{1}$ state) at $60 \mathrm{GHz}$. Compared to the phase shifters of Tab. I, the circuit presents state-of-the-art performance.

The measured phase shift is $22.2^{\circ}$, quite close to the $22.5^{\circ}$ modeled. 18 phase shifters have been measured: $13(72 \%)$ are functional. The phase shifts in worst case are $17.1^{\circ}$ and $32.7^{\circ}$, respectively. These large variations are due to the fact that the used RF MEMS technology is still under development.

\section{CONCLUSION}

This paper presents an approach to millimeter-wave circuit design based on MEMS models. These models are completely frequency scalable over the entire millimeter-wave band, by using the methodology based on the scaling parameter $K_{s}$. Indeed, the measured switches exhibit good characteristics very close to the ones obtained by the developed MEMS capacitive shunt switch model.

This model was used to design high performance circuits based on RF MEMS shunt switches, for example the presented $60-\mathrm{GHz}$ loaded-line phase shifter. 
At millimeter wave frequencies, a similar approach is also possible for DC-contact switches. Further extensions towards rapid prototyping of RF MEMS based circuits like tuners and phase shifters can be prospected.

\section{ACKNOWLEDGMENT}

The authors would like to thank A. Rumeau and J. Lattes for measurement and T. Beluch for Matlab assistance.

\section{REFERENCES}

[1] Juo-Jung Hung, L. Dussopt, G.M. Rebeiz, "Distributed 2- and 3-bit Wband MEMS phase shifters on glass substrates," IEEE Transactions on Microwave Theory and Techniques, Volume 52, Issue 2, p 600 - 606, Feb. 2004

[2] K. Hong-Teuk, P. Jae-Hyoung, L. Sanghyo, K. Seongho, K. Jung-Mu, K. Yong-Kweon, K. Youngwoo, "V-band 2-b and 4-b low-loss and lowvoltage distributed MEMS digital phase shifter using metal-air-metal capacitors," IEEE Transactions on Microwave Theory and Techniques, Volume 52, Issue 2, p. 600-606, Feb 2004.

[3] M. Byung-Wook, G.M. Rebeiz, "Ka-Band BiCMOS 4-Bit Phase Shifter with Integrated LNA for Phased Array T/R Modules," Microwave Symposium, IEEE/MTT-S International, p. 479-482, 3-8 June 2007.

[4] K. Kwang-Jin, G.M. Rebeiz, "0.13- $\mu$ m CMOS Phase Shifters for X-, $\mathrm{Ku}-$, and K-Band Phased Arrays," IEEE Journal of Solid State Circuits, Volume 4, pp. 2535-2546, November 2007.

[5] Yu, Yikun; Baltus, Peter; van Roermund, Arthur; Jeurissen, Dennis; de Graauw, Anton; van der Heijden, Edwin; Pijper, Ralf, "A $60 \mathrm{GHz}$ digitally controlled phase shifter in CMOS," ESSCIRC 2008, pp. 250253, Sept. 2008

[6] J.Y. Qian, G.P. Li, F. De Flaviis, "A parametric model of low-loss RF MEMS capacitive switches," Asia-Pacific Microwave Conference, APMC 2001, Volume 3, pp. 1020 - 1023, 3-6 Dec. 2001.

[7] J.B. Muldavin, G.M. Rebeiz, "High-isolation CPW MEMS shunt switches. 1. Modeling," Microwave Theory and Techniques, IEEE Transactions on, Volume 48, Issue 6, pp. 1045 - 1052, June 2000.

[8] G. Bartolucci, R. Marcelli, S. Catoni, B. Margesin, F. Giacomozzi, A. Lucibello, V. Mulloni, P. Farinelli, "Circuital Modelling of Shunt Capacitive RF MEMS Switches," European Microwave Integrated Circuit Conference, EuMIC 2008, pp. 362 - 365, 27-28 Oct. 2008.

[9] S. Halder, C. Palego, Zhen Peng, J.C.M. Hwang, D.I. Forehand, C.L. Goldsmith, "Compact RF Model for Transient Characteristics of MEMS Capacitive Switches," IEEE Transactions on Microwave Theory and Techniques, Volume 57, Issue 1, pp. 237 -242, Jan. 2009

[10] R. Marcelli, A. Lucibello, G. De Angelis, E.Proietti, D. Comastri, "Mechanical modelling of capacitive RF MEMS shunt switches," Symposium on Design, Test, Integration \& Packaging of MEMS/MOEMS, MEMS/MOEMS '09, pp. 19-22, 1-3 April 2009.

[11] V. Puyal, D. Dragomirescu, C. Villeneuve, J. Lattes, J. Ruan, P. Pons and R. Plana, "RF MEMS Design for Phase Shifters from K-band up to W-band," Asia-Pacific Microwave Conference, APMC 2008, Hong Kong, 16-20 Dec. 2008.

[12] C. Bordas, K. Grenier, D. Dubuc, M. Paillard and J.-L. Cazaux, "High quality medium power RF-MEMS based impedance tuner for smart microsystem integration," Prime 2007, Bordeaux, France, July 2007.

[13] G. M. Rebeiz, "RF MEMS: Theory, Design, and Technology," Wiley, Chapter 4, pp. 87-120, March 2003.

[14] V. Puyal, D. Dragomirescu and R. Plana, "A New Approach to RF MEMS Shunt Switch modeling from K-band up to W-band," ATOM-N 2008, Constanta, Romania, August 2008.

[15] B.C. Wadell, "Modeling Circuit Parasitics: Part 2," IEEE Instrumentation \& Measurement Magazine, Vol. 1, Issue 2, pp. 6-8, June 1998.

[16] G. M. Rebeiz, "RF MEMS: Theory, Design, and Technology," Wiley, pp. 89-90, March 2003.

[17] G. M. Rebeiz, "RF MEMS: Theory, Design, and Technology," Wiley, pp. 36-38, March 2003.
[18] Harry A. Atwater, "Circuit design of the loaded-line phase shifter," IEEE Trans. Microwave Theory Tech.,. vol. 33, pp. 626-634, July 1985.

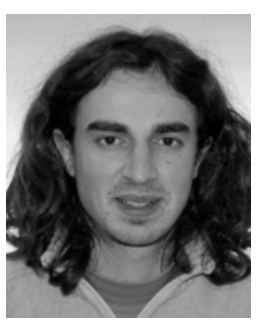

Vincent Puyal (S'04-M'08) was born in Montpellier, France in 1977. He received the B.S. degree in electronics engineering from Polytech'Montpellier, Univesity of Montpellier II in 2002, and the Ph.D. degree in microelectronics engineering from the University of Montpellier II in 2007.

From 2002 to 2006, he worked on design and testing of high-speed bipolar ICs for optical communication systems in collaboration with the "Laboratoire de Robotique, d'Informatique et de Microélectronique de Montpellier" (LIRMM), Montpellier, and "Alcatel-Thales III-V Lab", Marcoussis, France.

In 2007, he joined the "Laboratoire d'Architecture et d'Analyse des Systèmes" (LAAS-CNRS), University of Toulouse in Toulouse, France. His current research interests include design of RF MEMS components and ICs for wireless communication systems.

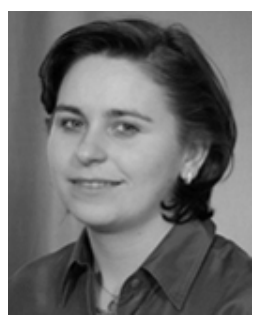

Daniela Dragomirescu (M'96) was born in Bucharest, Romania in 1972. She received the Electronics and Telecommunication engineering degree from Bucharest Polytechnic University, Romania in 1996 and her Ph.D. degree from the National Institute of Applied Sciences, Toulouse, France.

She is an Associate Professor at National Institute of Applied Sciences, Toulouse and a researcher at Laboratory for analysis and Systems' Architecture (LAAS-CNRS). Her main research interests are in the Wireless Sensor Network, system architecture and modeling and circuits design.

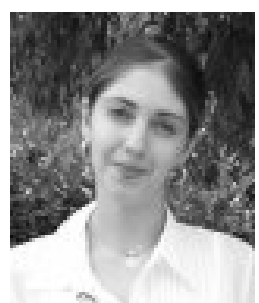

Christina Villeneuve was born in France in 1981. She received an engineering degree in materials physic and nanophysics from Institut National Polytechnique Grenoble (France) in 2004 and a PhD. Degree in materials physic from University of Toulouse (France) in 2007.

From 2004 to 2007, she worked in the Research Department of SOITEC SA and in the CEMES to develop a non destructive method, using Raman spectroscopy, to quantify damage and stress induced during light ions implantation. Since 2007, she worked in LAAS to improve RF-MEMS micro-switches fabrication process and to study microstructure of metallic thin layer.

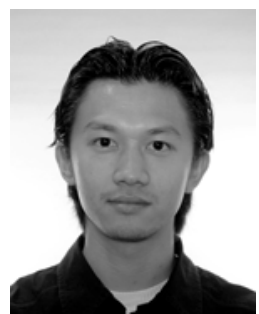

Jinyu Ruan (S'07) was born in Guang Dong, China and grew up in French Guiana, where he received his Bachelor's degree in Electronics, Electrical Engineering and Automation. He received the Master of Science degree in Electrical Engineering for High Frequency Broadband Systems from the University of Marne la Vallée, Paris, France in 2006. Before starting his Ph.D. he did six months training on fabrication of photo detectors using silicon with MEMS technology processes.

$\mathrm{He}$ is currently working toward the Ph.D. degree at the Laboratoire d'Architecture et d'Analyse des Systèmes at the Centre National de la Recherche Scientifique (LAAS-CNRS) University of Toulouse in Toulouse, France. His Ph.D. studies are supported by several research projects involved in reliability of RF MEMS, from design modelling to testing. His main field of interest is in the electrical characterization of RF MEMS, particularly the dielectric charging effects and electro-static discharges failures. 


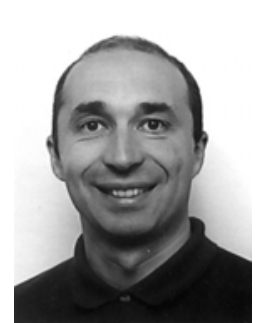

Patrick Pons received his "Doctorat" in electronics from Paul Sabatier University, Toulouse, France, in 1990. Since 1991 he is a researcher in the CNRSLAAS (National Scientific Research Center Laboratory of Analysis and Architecture of Systems) in Toulouse.

His research interests are focused in microtechnology and microsensors. In 1995, he started in the lab the study on microtechnology for microwave applications. Now he manages the development of this technology for high frequency Microsystems and develops also pressure sensors for specific applications.

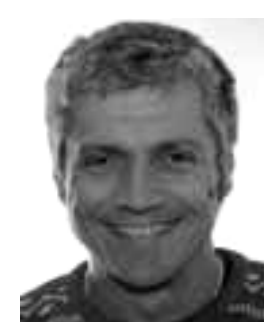

Robert Plana (M'98-SM'08) was born on March 1964 In Toulouse. He obtained its PhD in 1993 at LAAS-CNRS and Paul Sabatier University on the Noise modeling and characterization of Advanced Microwave devices (HEMT, PHEMT and HBT) that includes the reliability. In 1993, as associate professor at LAAS-CNRS, he has started a new research area concerning the investigation of millimeterwave capabilities of Silicon based technologies. More precisely, he has focussed on the microwave and millimeterwave properties of SiGe devices and their capabilities for low noise circuits.

In 1995, he has started a new project concerning the improvement of the passives on silicon through the use of MEMS technologies. In 1999, he has been involved with SiGe Semi-conductor in Ottawa where he was working on the low power and low noise integrated circuits for RF applications. In the same year, he has received a special award from CNRS for his works on Silicon based technologies for millimeterwave communications. In 2000, he has been professor at Paul Sabatier University and Institut Universitaire de France and he has started a research team at LAAS-CNRS in the field of Micro and Nanosystem for RF and millimeterwave communications. Its main interests are on the technology, design, modelling, test, characterization and reliability of RF MEMS for low noise and high power millimeterwave applications and the development of the MEMS IC concept for smart microsystem. He has built a network of excellence in Europe in this field "AMICOM" regrouping 25 research groups. He has authored and co-authored more than 200 international journals and conferences. In 2004, he has been appointed as Deputy Director of the Information and Communication Department at the CNRS Headquarter. From January 2005 to January 2006, he has been appointed director of the Information and Communication Department at CNRS. He is now heading a research group at LAAS-CNRS in the field of Micro and Nanosystem for wireless communications. 